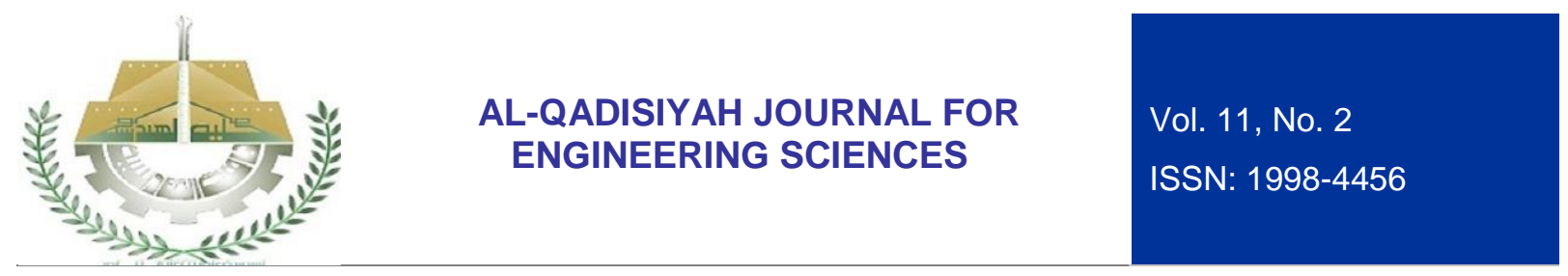

\title{
EVALUATING THE PERFORMANCE OF ASPHALT RIENFORCEMENT LAYER COMPRISING POLYPROPYLENE GRANULES
}

\author{
Hayder Salman Khudhair, \\ ASS.Lecturer MSc., Department. of Civil Engineering, University of Kerbala, Karbala, Iraq \\ E mail: hayder.salman83@gmail.com \\ Mustafa Amoori Kadhim, \\ MSc., Department. of Civil Engineering., University of Kerbala, Karbala, Iraq \\ E mail: mostafaamore9@gmail.com
}

\begin{abstract}
Despite the widespread use of hot mix asphalt (HMA) Overlay as one of the most important methods of pavement maintenance, rehabilitation and development of roads, also the ease and speed of implementation and low costs, there are many disadvantages and problems that accompany the use, which is mostly due to reflection of the defects of layers the old pavement on which the asphalt reinforcement layer is based. Therefore, this study aims to prepare an asphalt mixture with a high performance and good specifications as overlay layer, which can resist the problems and defects that are exposed to it and increase its service life. Polypropylene granules of $19 \mathrm{~mm}$ particles size were used as an additive to the asphalt binder (AC 60-70), with percentages 1, 2, 3, 4, 5 and 7\% of the optimum asphalt content weight. The volumetric and mechanical characteristics of mixture with this addition were evaluated by using Marshall stability and indirect tensile testing (ITS). The study showed that the use of $4 \%$ of the polypropylene granules of optimum asphalt weight gave optimal performance compared to the unmodified mix. The optimum performance of the asphalt concrete overlay during its design life, especially at high temperatures, was improved by improving the physical and mechanical properties of the asphalt mixture and by increasing its resistance to stresses is $32 \%$.
\end{abstract}

Keywords: Polypropylene granules, Asphalt reinforcement layer, Indirect tensile strength, hot mix asphalt, vertical and horizontal deformations.

\section{INTRODUCTION}

Introducing a traditional road pavement with hot asphaltic mixtures to withstand heavy vehicles axle load at high temperature is not good choice if mixture left without any addition of binder modifiers or any other techniques. The rapid growth of community may be the main cause for deteriorating of hot mixtures pavement due to increasing traffic load.

Numerous Researchers had forced in their researches to produce a new hot mixtures that can withstand any remain in service for longer time against adverse climate and traffic conditions, such as polymer. 


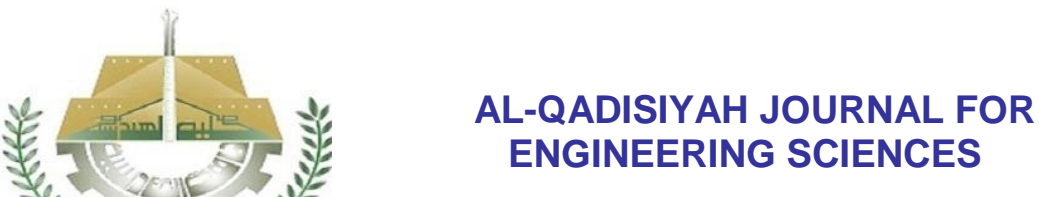

Vol. 11, No. 2

ISSN: $1998-4456$

Polymer modified asphalt binder, this name is usually called when polymer is added to asphaltic mixtures with specific method to improve mix properties and accelerate pavement failure, and reduce reflective cracking (Button and Lytton, 2007). Polypropylene is one of most common types of plastomers polymer that can be added to asphalt mixes to enhance performance, improve mix resistance to deformation under a wide range of varying temperatures (Kalantar et al., 2012). It can be utilized by using either the dry method, which the polymer is added to aggregate before bitumen addition, or mixed with bitumen at sufficient temperature (usually not less than $170 \mathrm{C}$ ), the latter called wet method (Khan et al., 2009). The wet process is more common method than dry process (Polacco et al., 2005).

Awwad and Shbeeb (2007) studied such type of polymer on hot mixtures using the dry process. They blended polymer with the bitumen with $(6,8,10,12,14,16$ and $18 \%)$ from bitumen weight. They concluded that addition of $12 \%$ of polymer at optimum asphalt content reflected better engineering properties that untreated mixes, in term of mechanical and volumetric properties.

Navarro et al. (2007) Revealed in their study that Polymers can significantly improve the asphalt pavements performance at low, intermediate and high temperatures. They can increase the resistance of mixture to permanent deformation, thermal fracture and fatigue cracking at low temperature, decrease plastic flow and increase shear modulus at high temperature

Abd-A.M.Al-D (2003) studied the effect of three different types of polymers with different percentages on the specifications of asphalt mixtures: high density polyethylene (HDPE) and styrene butadiene rubber. The addition of hydrate and HDPE as additives to asphalt mixtures improved their resistance of the tensile and its resistance to the impact of water. Also, addition $8 \%$ of the weight of asphalt of HDPE increases the resistance of asphalt mix for the tensile strength about $38.7 \%$.

In this research polyethylene, which is one type of plastomers, has utilized using the wet process, to modify asphalt mix properties. The principle objectives of this research were to:

1- $\quad$ Enhance mixture resistance to thermal cracking.

2- Improve mix stability and reduce vertical and horizontal deformations.

3- Determination the optimum polymer content that enhance mix performance and keep other properties within the specifications, after selecting the optimum bitumen content in the mix.

\section{MATERIALS}

- $\quad$ The middle values of Aggregate gradation was selected for wearing layer type 3B with max size of $9.5 \mathrm{~mm}$ as specified in the Iraqi limitations (GSRB, 2003). Coarse and fine aggregates were provided from local Karbala quarries, and their properties are presented in Table 1.

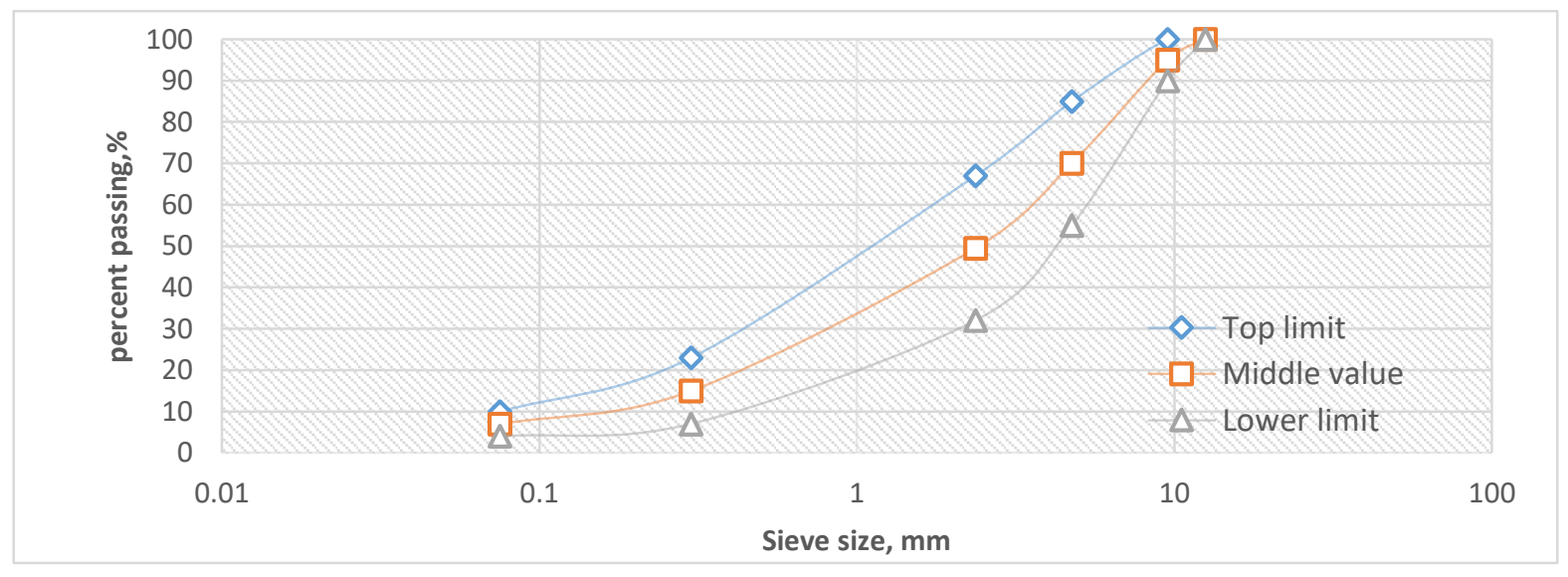

Figure 1 Particle size distribution for wearing layer type 3B, (GSRB, 2003) 


\section{AL-QADISIYAH JOURNAL FOR ENGINEERING SCIENCES}

Vol. 11, No. 2

\section{ISSN: $1998-4456$}

- $\quad$ Ordinary Portland Cement (OPC) was utilized as filler in this research, which was provided by Karbala cement Plant.

- $\quad$ Asphalt binder was provided by the Doura refinery with grade (AC 40-50), its properties are presented in Table 2.

- $\quad$ Polymeric materials: Polypropylene was used in granules form which were prepared from local markets in Karbala. It was availability, wide applications and special characteristics, particularly thermal properties. The specification and basic characteristics of the propylene granules that used in the research were determined by the manufacturer and as shown in Table (3).

Table 1 The physical Properties for Filler, Coarse and Fine Aggregate

\begin{tabular}{|c|c|c|c|c|c|c|}
\hline Material & $\begin{array}{c}\text { Appearance } \\
\text { specific } \\
\text { gravity }\end{array}$ & $\begin{array}{c}\text { G sb } \\
\text { (SSD) }\end{array}$ & G sb (Dry) & Gse & $\begin{array}{c}\text { Water } \\
\text { Absorption, \% }\end{array}$ & $\begin{array}{c}\text { Specification } \\
\text { ASTM [18] }\end{array}$ \\
\hline $\begin{array}{c}\text { Coarse } \\
\text { aggregate }\end{array}$ & 2.603 & 2.576 & 2.535 & 2.569 & 2.33 & C127-88 \\
\hline Fine aggregate & 2.692 & 2.663 & 2.647 & 2.670 & 0.50 & C128-97 \\
\hline Filler & 2.720 & - & - & 2.720 & - & C128-97 \\
\hline $\begin{array}{c}\text { Los-Angeles } \\
\text { Abrasion, \% }\end{array}$ & $33<35$ & C131-96 \\
\hline $\begin{array}{c}\text { Sand } \\
\text { Equivalent, \% }\end{array}$ & $63>50$ & D2419-95 \\
\hline
\end{tabular}

Table 2 Properties of asphalt binder

\begin{tabular}{|l|l|l|l|}
\hline Property & Test Values & ASTM Designation & Acceptable limit \\
\hline Penetration, $100 \mathrm{gm} ., 25^{\circ} \mathrm{C}, 5 \mathrm{sec}(1 / 10 \mathrm{~mm})$ & 43 & D5 (ASTM, 2015b) & $40-50$ \\
\hline Specific Gravity, $25^{\circ} \mathrm{C}(\mathrm{gm} . / \mathrm{cm} 3)$ & 1.03 & D70 (ASTM, 2009) & $1.02-1.04$ \\
\hline Ductility, $25^{\circ} \mathrm{C}, 5 \mathrm{~cm} / \mathrm{min}(\mathrm{cm})$ & $>100$ & D113 (ASTM, 2007) & $>100$ \\
\hline Flash Point, ( C ) & 318 & D92 (ASTM, 2005) & $>240$ \\
\hline Softening Point (CC) & 47 & D36 (ASTM, 2000) & $40-50$ \\
\hline \multicolumn{1}{|c|}{ Loss of weight $50 \mathrm{gm}, 163^{\circ} \mathrm{C}, 5 \mathrm{~h}$} & 0.248 & D 1754 (ASTM, 2014) & $\leq 0.80$ \\
\hline
\end{tabular}

Table 3 properties of polypropylene polymer

\begin{tabular}{|c|c|c|}
\hline properties & $\begin{array}{c}\text { Specification } \\
\text { ASTM [18] }\end{array}$ & Value \\
\hline Melt Flow Index, gr/10min & D1238 & 10 \\
\hline Density, $\mathrm{gr} / \mathrm{cm}^{\wedge} 3$ & D1505 & 0.943 \\
\hline Softening Point, $^{\circ} \mathrm{C}$ & D1525B & 135 \\
\hline
\end{tabular}




\section{AL-QADISIYAH JOURNAL FOR ENGINEERING SCIENCES}

Vol. 11, No. 2

ISSN: 1998-4456

\section{EXPERIMENTAL PROGRAM: DESIGN ASPHALT MIXTURE AND EFFECT OF ADDITION OF POLYPROPYLENE GRANULES ON THE PROPERTIES OF ASPHALT MIXTURES}

Marshall test design method is considered common method for determining amount of required bitumen in the mixture that reflected best mechanical and volumetric properties, as will be clarified later. The study will include design of reference mixture without polymer for comparison and to clear effect of polymer.

\subsection{DESIGN OF THE REFERENCE ASPHALT MIXTURE}

The asphalt mixture was designed according to Marshall's design method (ASTM, 2015a). Six percentages of asphalt $(4,4.5,5,5.5,6$ and 6.5$)$ were added as a percentage of the weight of the asphalt mixture. Then, volumetric properties and Marshall test were determined for each percentage to select the optimum percentage of asphalt content. The selected percentage must meet the design requirements of Marshall Method. The following tables describes Marshall stability and flow result (table 4) and the volumetric properties results (table 4 and 5):

Table 4 Marshall stability (MS) and Marshall flow (MF) of Asphalt Mixture with The Different Percentage of Asphalt

\begin{tabular}{|c|c|c|c|c|c|c|c|}
\hline $\begin{array}{l}\text { asphalt } \\
(\%)\end{array}$ & $\begin{array}{l}\text { Height of specimen } \\
\qquad(\mathrm{mm})\end{array}$ & $\begin{array}{l}\text { Cor. } \\
\text { Factor }\end{array}$ & $\begin{array}{l}\mathrm{MS} \\
(\mathrm{KN})\end{array}$ & $\begin{array}{l}\text { Cor. MS } \\
(\mathrm{KN})\end{array}$ & $\begin{array}{l}\text { Av. Cor. MS } \\
(\mathrm{KN})\end{array}$ & $\begin{array}{l}\text { Flow } \\
(\mathrm{mm})\end{array}$ & $\begin{array}{l}\text { Av. Flow } \\
(\mathrm{mm})\end{array}$ \\
\hline \multirow{3}{*}{4} & 58.2 & 1.14 & 8.64 & 9.85 & \multirow{3}{*}{10.37} & 2.70 & \multirow{3}{*}{2.57} \\
\hline & 61.0 & 1.04 & 9.33 & 9.70 & & 2.55 & \\
\hline & 62.0 & 1.00 & 11.58 & 11.58 & & 2.45 & \\
\hline \multirow{3}{*}{4.5} & 63.0 & 1.00 & 13.98 & 13.98 & \multirow{3}{*}{14.02} & 2.90 & \multirow{3}{*}{2.57} \\
\hline & 61.5 & 1.04 & 13.98 & 14.54 & & 2.80 & \\
\hline & 64.0 & 1.00 & 13.54 & 13.54 & & 3.05 & \\
\hline \multirow{3}{*}{5} & 70.0 & 0.86 & 15.31 & 13.17 & \multirow{3}{*}{13.19} & 3.30 & \multirow{3}{*}{3.38} \\
\hline & 59.0 & 1.14 & 13.37 & 15.24 & & 3.40 & \\
\hline & 68.0 & 0.89 & 12.52 & 11.15 & & 3.45 & \\
\hline \multirow{3}{*}{5.5} & 67.5 & 0.89 & 8.09 & 7.20 & \multirow{3}{*}{9.58} & 3.65 & \multirow{3}{*}{3.65} \\
\hline & 70.0 & 0.86 & 12.53 & 10.77 & & 3.60 & \\
\hline & 73.5 & 0.81 & 13.29 & 10.77 & & 3.70 & \\
\hline \multirow{3}{*}{6} & 65.0 & 0.96 & 10.19 & 9.78 & \multirow{3}{*}{8.93} & 4.60 & \multirow{3}{*}{4.63} \\
\hline & 63.0 & 1.00 & 8.20 & 8.20 & & 4.50 & \\
\hline & 63.5 & 1.00 & 8.80 & 8.80 & & 4.80 & \\
\hline \multirow{3}{*}{6.5} & 74.5 & 0.78 & 8.16 & 6.36 & \multirow{3}{*}{6.98} & 6.05 & \multirow{3}{*}{5.93} \\
\hline & 67.0 & 0.89 & 6.49 & 5.78 & & 5.95 & \\
\hline & 66.5 & 0.93 & 9.48 & 8.81 & & 5.80 & \\
\hline
\end{tabular}


AL-QADISIYAH JOURNAL FOR ENGINEERING SCIENCES
Vol. 11, No. 2

ISSN: 1998-4456

Table 5 Properties of Asphalt Mixture with the Different Percentage of Asphalt content

\begin{tabular}{|c|c|c|c|c|c|c|}
\hline $\begin{array}{c}\text { Asphalt } \\
(\%)\end{array}$ & Specimen & Gmb & Av.Gmb & Gmm & $\begin{array}{r}\begin{array}{r}\text { Air void } \\
(\%)\end{array} \\
\end{array}$ & $\begin{array}{c}\text { Av. Air void } \\
(\%)\end{array}$ \\
\hline \multirow{3}{*}{4} & A 01 & 2.294 & \multirow{3}{*}{2.260} & 2.459 & 6.67 & \multirow{3}{*}{8.09} \\
\hline & A02 & 2.234 & & 2.459 & 9.13 & \\
\hline & A03 & 2.251 & & 2.459 & 8.46 & \\
\hline \multirow{3}{*}{4.5} & A11 & 2.325 & \multirow{3}{*}{2.307} & 2.431 & 4.37 & \multirow{3}{*}{5.08} \\
\hline & $\mathrm{A} 12$ & 2.312 & & 2.431 & 4.89 & \\
\hline & A13 & 2.285 & & 2.431 & 5.99 & \\
\hline \multirow{3}{*}{5} & A21 & 2.340 & \multirow{3}{*}{2.317} & 2.408 & 2.83 & \multirow{3}{*}{3.80} \\
\hline & A22 & 2.320 & & 2.408 & 3.64 & \\
\hline & A23 & 2.290 & & 2.408 & 4.92 & \\
\hline \multirow{3}{*}{5.5} & A31 & 2.338 & \multirow{3}{*}{2.337} & 2.385 & 1.99 & \multirow{3}{*}{2.00} \\
\hline & A32 & 2.327 & & 2.385 & 2.44 & \\
\hline & A33 & 2.348 & & 2.385 & 1.57 & \\
\hline \multirow{3}{*}{6} & A41 & 2.355 & \multirow{3}{*}{2.354} & 2.382 & 1.11 & \multirow{3}{*}{1.17} \\
\hline & A42 & 2.344 & & 2.382 & 1.58 & \\
\hline & A43 & 2.362 & & 2.382 & 0.82 & \\
\hline \multirow{3}{*}{6.5} & A51 & 2.351 & \multirow{3}{*}{2.348} & 2.375 & 1.02 & \multirow{3}{*}{1.14} \\
\hline & A52 & 2.351 & & 2.375 & 1.02 & \\
\hline & A53 & 2.343 & & 2.375 & 1.36 & \\
\hline
\end{tabular}

Table 6 Volumetric Properties of the trial Asphalt Mixtures

\begin{tabular}{|c|c|c|c|c|c|c|c|}
\hline Av.V.F.A, (\%) & $\begin{array}{c}\text { V.F.A, } \\
(\%)\end{array}$ & $\begin{array}{c}\text { Av. } \\
\text { V.M.A } \\
(\%)\end{array}$ & $\begin{array}{c}\text { V.M.A, } \\
(\%)\end{array}$ & $\begin{array}{c}\% \\
\text { Passing }\end{array}$ & Gsb & specimen & $\begin{array}{c}\text { Asphalt } \\
(\%)\end{array}$ \\
\hline \multirow{3}{*}{50.61} & 55.56 & \multirow{3}{*}{16.30} & 15.01 & 96.00 & 2.592 & A01 & \multirow{3}{*}{4.0} \\
\hline & 47.09 & & 17.25 & 96.00 & 2.592 & A02 & \\
\hline & 49.17 & & 16.64 & 96.00 & 2.592 & A03 & \\
\hline \multirow{3}{*}{66.21} & 69.55 & \multirow{3}{*}{14.98} & 14.34 & 95.50 & 2.592 & A11 & \multirow{3}{*}{4.5} \\
\hline & 66.99 & & 14.81 & 95.50 & 2.592 & A12 & \\
\hline & 62.08 & & 15.80 & 95.50 & 2.592 & A13 & \\
\hline \multirow{3}{*}{75.04} & 80.13 & \multirow{3}{*}{15.08} & 14.23 & 95.00 & 2.592 & A21 & \multirow{3}{*}{5.0} \\
\hline & 75.62 & & 14.95 & 95.00 & 2.592 & A22 & \\
\hline & 69.37 & & 16.08 & 95.00 & 2.592 & A23 & \\
\hline \multirow{2}{*}{86.50} & 86.54 & \multirow[b]{2}{*}{14.77} & 14.76 & 94.5 & 2.592 & A31 & \multirow[b]{2}{*}{5.5} \\
\hline & 83.88 & & 15.16 & 94.5 & 2.592 & A32 & \\
\hline
\end{tabular}




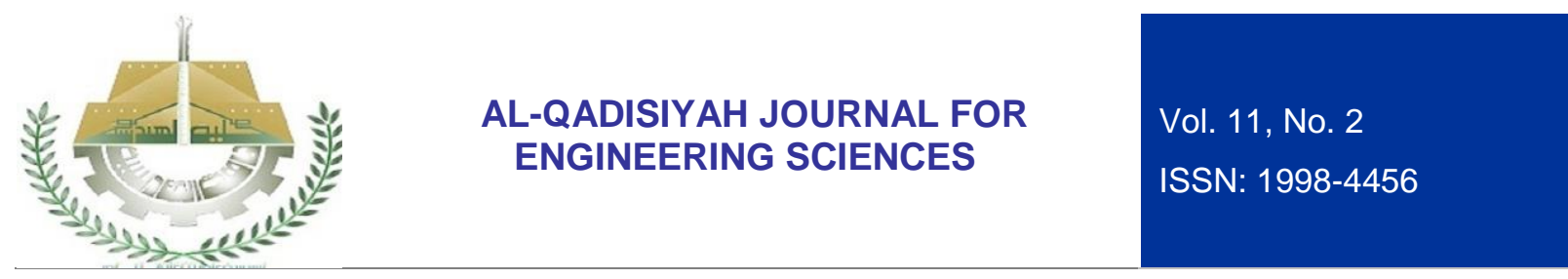

\begin{tabular}{|c|c|c|c|c|c|c|c|}
\hline & 89.09 & & 14.40 & 94.5 & 2.592 & А33 & \\
\hline \multirow{3}{*}{92.06} & 92.42 & \multirow{3}{*}{14.63} & 14.58 & 94.00 & 2.592 & A41 & \multirow{3}{*}{6.0} \\
\hline & 89.48 & & 14.98 & 94.00 & 2.592 & A42 & \\
\hline & 94.28 & & 14.33 & 94.00 & 2.592 & A43 & \\
\hline \multirow{3}{*}{92.58} & 93.26 & \multirow{3}{*}{15.28} & 15.19 & 93.50 & 2.592 & A51 & \multirow{3}{*}{6.5} \\
\hline & 93.28 & & 15.19 & 93.50 & 2.592 & A52 & \\
\hline & 91.19 & & 15.48 & 93.50 & 2.592 & A53 & \\
\hline
\end{tabular}

After determining the properties of Marshall, the relationship between the added asphalt ratio and each of the characteristics given by the Marshall test was measured (Marshall stability, Marshall flow, volumetric weight, air void, V.M.A, V.F.A) $(1,2,3,4,5,6)$ respectively, and by studying and analysing the resulting curves in the previous forms we find that:

1. Figure 2 shows that the value of Marshall stability increases by increasing the percentage of asphalt to reach a maximum stability value, after which the stability value tends to decrease with the increase of the asphalt percentage. This explains that when the asphalt percentage is low, the cohesion between the coarse and fine aggregates is weak, Asphalt, which plays the role of the bonding material, becomes more cohesive until reaching the maximum value of stability. The value of stability decreases after the added asphalt percentage becomes large. This reduces the cohesion between the coarse and fine aggregates and facilitates their sliding on one another which causes the grains to float in the asphalt. Leads to a reduction in the value of the Marshall stability.

2. In Figure 3, it can be noticed that the value of the flow increases with the increase of the added asphalt percentage. This is explained by the increase in the percentage of added asphalt which facilitates the movement of the coarse and fine aggregates in the asphalt mixture and reduces the friction between them. Consequently, increasing the usability of slippage which increases the flow values.

3. Figure 4 shows that the volumetric weight expressed by the volumetric density of the asphalt mix increases with the percentage of asphalt until the curve reaches a maximum value. After this value, the volumetric weight decreases with the increase in the asphalt percentage. Which is due to increase the percentage of asphalt less the friction between the coarse and fine aggregate and easy to slip and move between them, which increases the effectiveness of the compaction. Consequently, increases the density of the asphalt mixture and continues this effect with increasing the percentage until it reaches to optimum value then plays the increase in the percentage of asphalt reverse role, leading to the spacing between grains, increase spaces and the lack of effective compaction, which leads to a decrease in the value of the volumetric weight and thus the volume density.

4. Figure 5 shows that the percentage of air void in the asphalt mix decreases with the increase in the asphalt percentage. This is due to the fact that the added asphalt is a part of it absorbed by the coarse and fine aggregate and fillers and its quantity is related to granular composition of the filler of the mixture. Whereas, the remaining asphalt, leads to coating the coarse and fine aggregate, and filler and performed the main function of asphalt as bonding of asphalt mixture. Performs the main asphalt function as a bonding material in the asphalt mixture, this part is called effective asphalt. Consequently, the increase in the asphalt content from the amount absorbed by the coarse and fine aggregates, filler and the required amount for coating the coarse and fine aggregates the coarse and fine aggregates which form an excess amount of asphalt will be formed to fill the remaining space between the coarse and fine aggregate coated with asphalt, thus reducing the percentage of air voids in the asphalt mix. 


\section{AL-QADISIYAH JOURNAL FOR ENGINEERING SCIENCES}

Vol. 11, No. 2

5. Figure 5 shows that the percentage of V.M.A in the asphalt mix decreases with the increase of the added asphalt percentage until reaching a small value for the percentage of V.M.A. V.M.A begins to increase with the increase of asphalt. Because, the asphalt helps to easy slipping the coarse and fine aggregate and fillers on each other. Increases the percentage of asphalt increases the effectiveness of compaction and the density of the asphalt mixture thus reduce the percentage of V.M.A, even reaching to the percentage that plays opposite role. Which, reduces the effectiveness of the compaction and thus mix asphalt density decreases and increases the percentage of voids between the coarse aggregate and fine materials and fillers in the asphalt mixture.

6. Figure 6 shows that the percentage of V.F.A increases with the increase in the percentage of added asphalt and curved asphalt as opposed to the curve formed from the ratio of the asphalt percentage with the air void in the asphalt mixture. This is due to the same discussion of Figure 5.

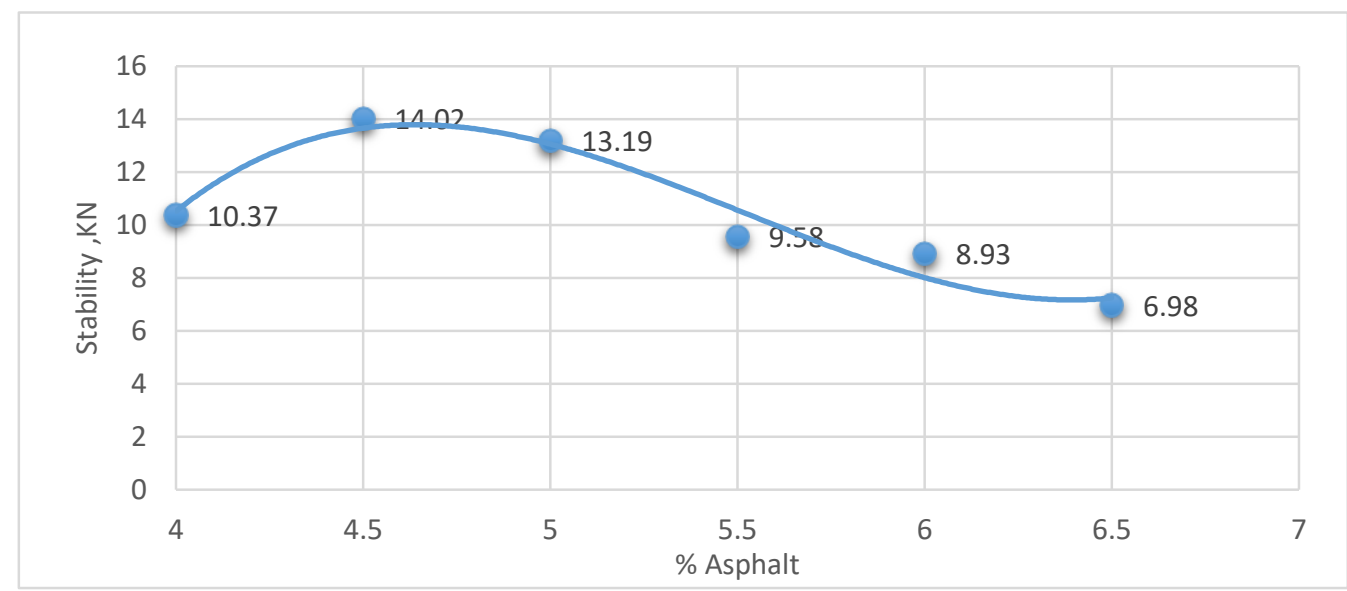

Figure 2 the relationship between Marshall stability and asphalt content

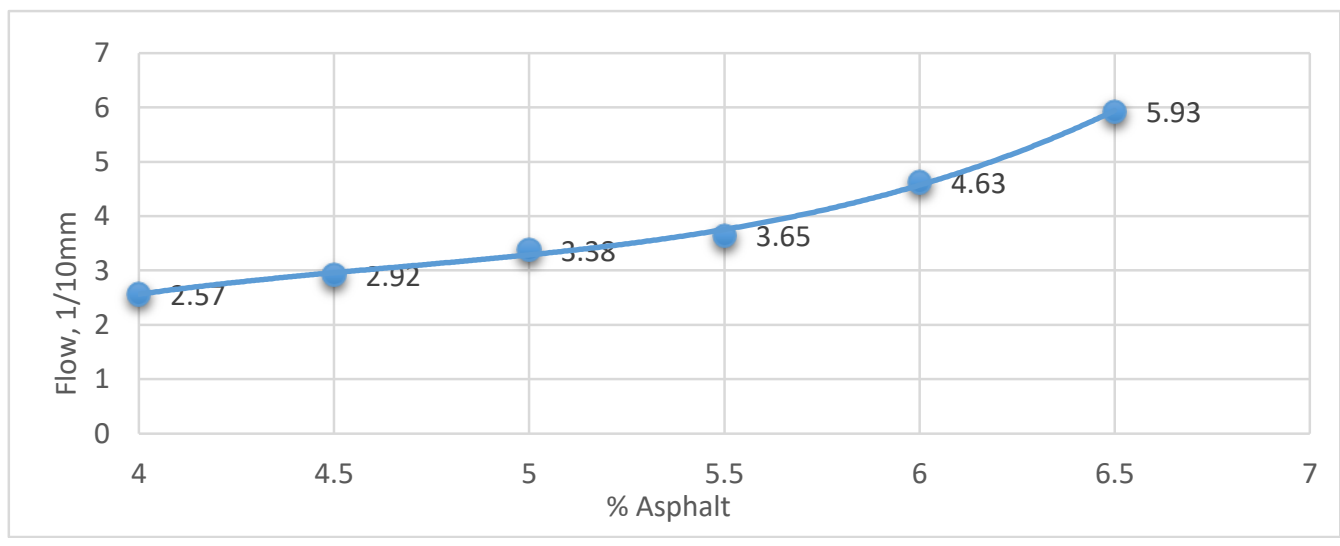

Figure 3 the relationship between Marshall flow (MF) and Asphalt content\% 


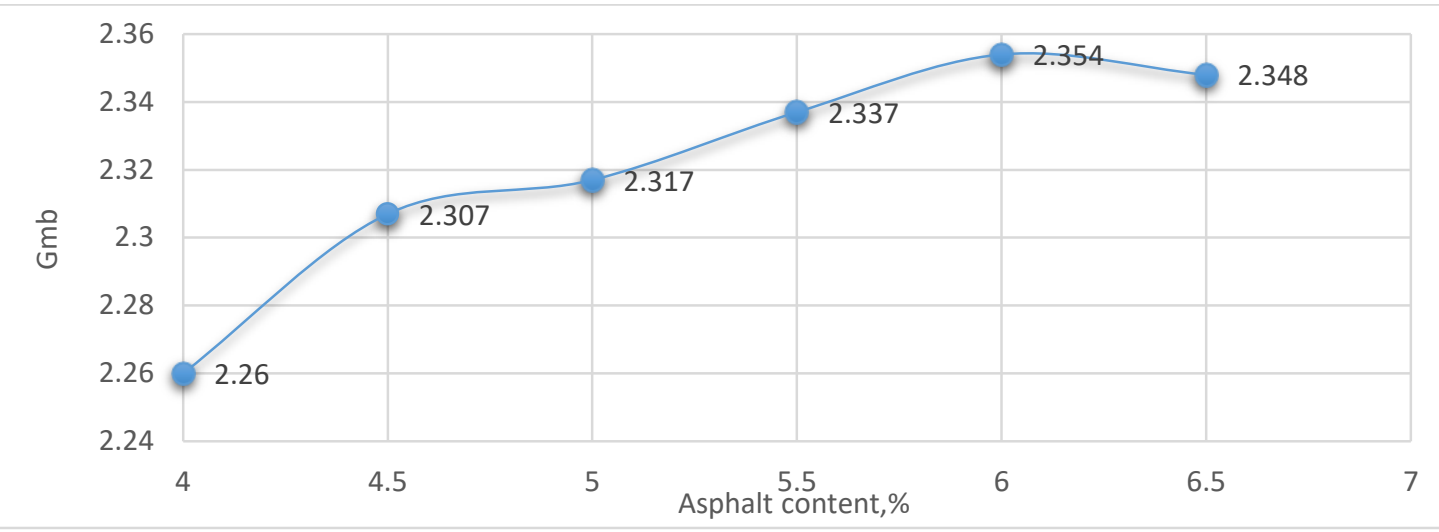

Figure 4 : The Relationship Between Asphalt content\% and Volumetric Specific Gravity (Gmb)

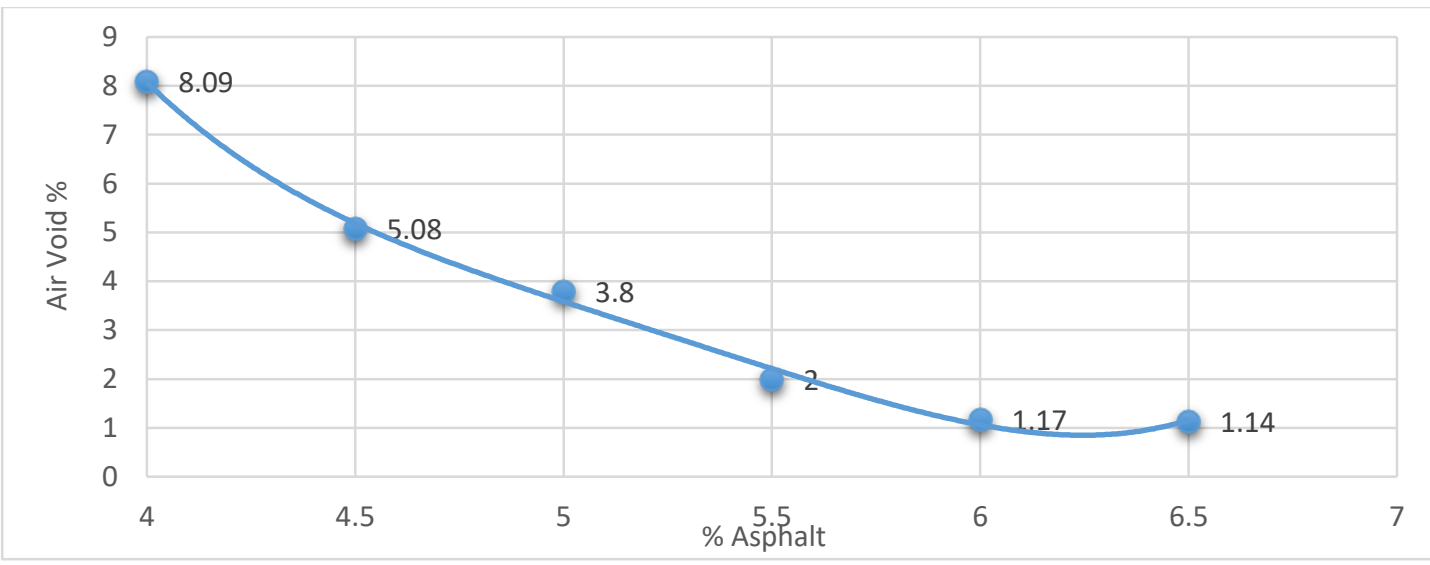

Figure 5 The Relationship Between \% Asphalt and Air Void Content

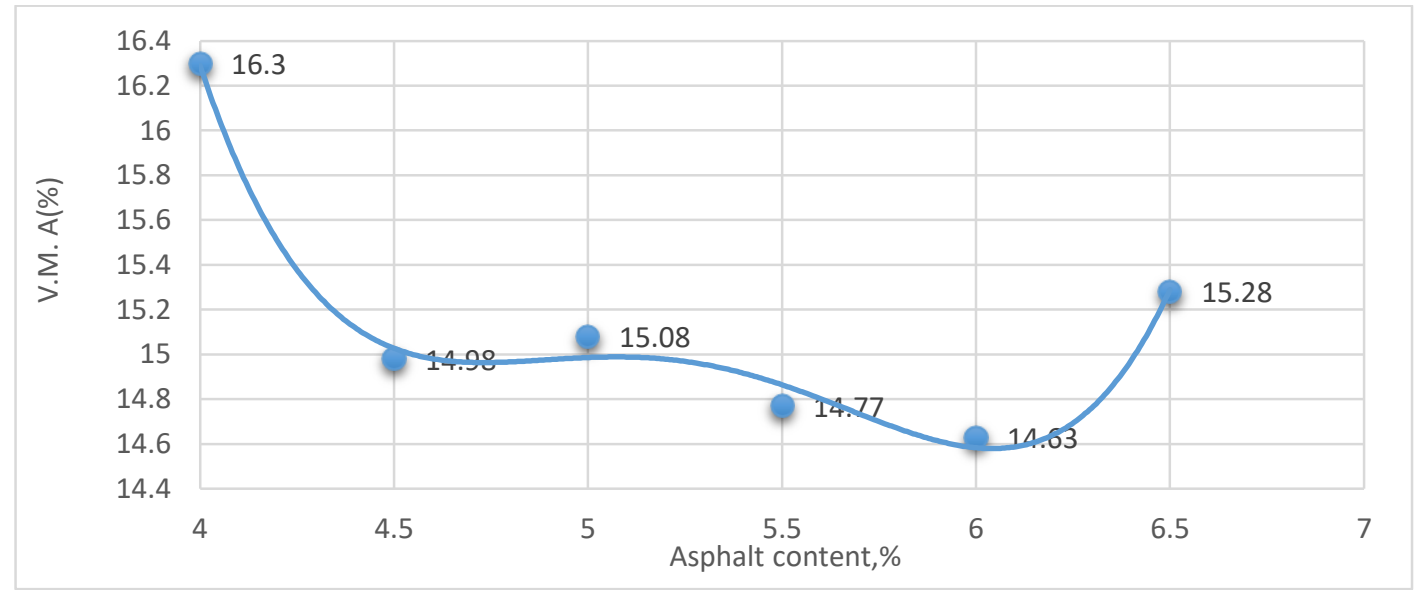

Figure 6 The Relationship Between \% Asphalt and V.M.A 

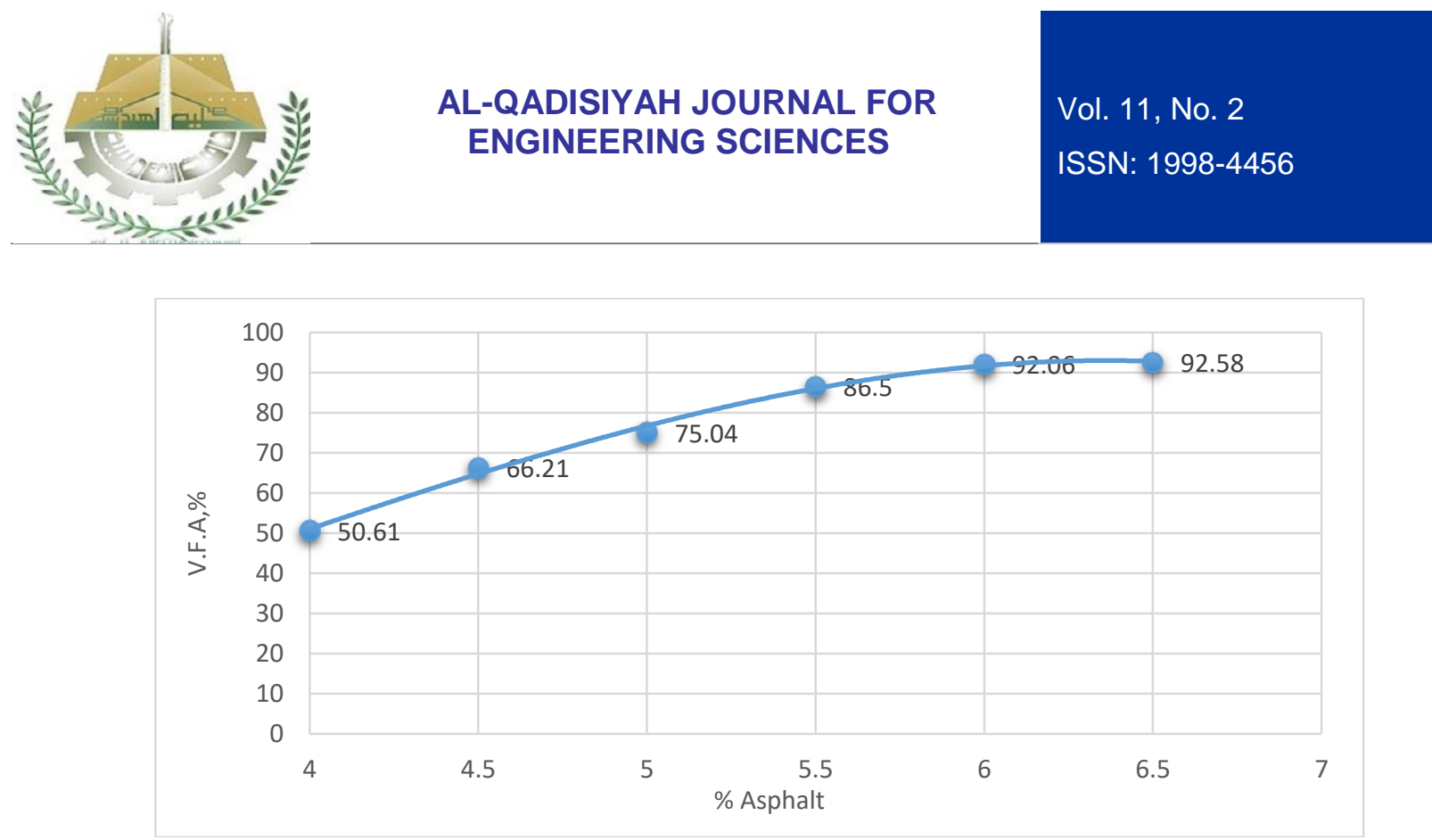

Figure 7 The Relationship Between \% Asphalt and V.F.A

7. Based on the previous figures, the percentage of (5.13\%) of the asphalt mixture was adopted as the optimum percentage that achieves the best values for the physical and mechanical properties of the asphalt mix. The selected percentage was within limitations of the Iraqi GSRB standards and reflected higher stability based on Marshall Design method for surface asphalt layer. The properties of the reference asphalt mix for the optimum asphalt percentage are shown in Table (7).

Table 7 Properties of Reference Asphalt Mixture compared with GSRB limitations

\begin{tabular}{|c|c|c|}
\hline Properties & Value & GSRB \\
\hline \% Optimum Asphalt Content & 5.13 & $3-7$ \\
\hline Marshall stability, KN & 13.8 & $\geq 8$ \\
\hline Marshall Flow, mm & 3 & $2-4$ \\
\hline (Gmb) & 2.319 & - \\
\hline Air Void, \% & 4.14 & $3-5$ \\
\hline V.M.A, \% & 14.91 & $\geq 14$ \\
\hline V.F.A, \% & 72.9 & $>70$ \\
\hline
\end{tabular}

\subsection{EFFECT OF ADDITION OF POLYPROPYLENE GRANULES ON THE PROPERTIES OF ASPHALT MIXTURES}

The effect of the addition of polypropylene granules on the properties of asphalt mixtures was studied by adding them to the asphalt binder in different percentages $(1,2,3,4,5,7 \%)$ of the weight of the asphalt. The wet process was followed for mixing the polymer with the bituemn (at optimum bitumen content). The method was achived by blending the polymer and the bitumen at temperture not less than $150 \mathrm{C}$ for $2 \mathrm{hr}$ to ensure mixture momogenitiy using high speed rotary mechnie mixer. The higher temperature of mixing facilities mixing process through reducing bitumen viscosity, and sufficient particles melting of the used polymer.Then, forming samples of the modified asphalt mixture in the previous proportions by three samples at least for each percentage of additive and take the mean value and compare it with unmodified samples with granules, depending on the characteristics given by the indirect tensile resistance test, and determine the best proportion of granules that gives better improvement in the properties of the asphalt mix.

\subsubsection{Indirect Tensile Strength Test (ITS)}

The indirect tensile strength test was performed based on (ASTM, 2012), and the determination of both the indirect tensile strength and the horizontal and vertical flow of the modified samples were made with 


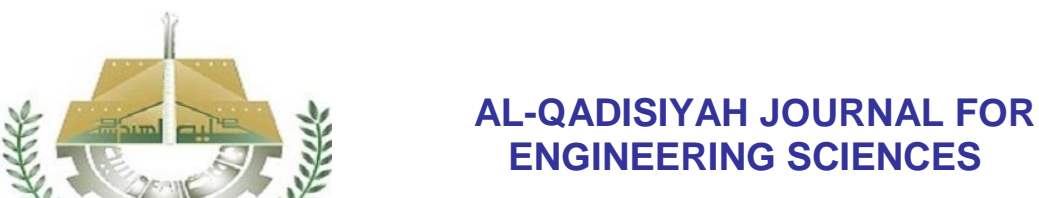

Vol. 11, No. 2

ISSN: 1998-4456

polypropylene granules for each percentage of the added granules as shown in Table 8 . The values of the physical properties of the asphalt mixture including indirect tensile test samples as shown in Table (9) volumetric weight, percentage of air spaces, percentage of coarse,fine aggregates, filler, percentage of asphalt-filled spaces.

Table 8 Properties of ITS test of Different Percentage of Polymer

\begin{tabular}{|c|c|c|c|c|c|c|c|c|}
\hline $\begin{array}{l}\text { Poly } \\
\text { mer } \\
(\%)\end{array}$ & SPEC. & $\begin{array}{l}\text { Load, P } \\
\text { (N) }\end{array}$ & $\begin{array}{l}\text { I.T.S } \\
\text { (Kpa ) }\end{array}$ & $\begin{array}{l}\text { Av. } \\
\text { I.T.S } \\
\text { (Kpa) }\end{array}$ & Flow (mm) & $\begin{array}{l}\text { Av. } \\
\text { Flow } \\
(\mathrm{mm})\end{array}$ & $\begin{array}{c}\text { Vertical } \\
\text { flow } \\
(\mathrm{mm})\end{array}$ & $\begin{array}{c}\text { Av. } \\
\text { Vertical } \\
\text { flow }\end{array}$ \\
\hline \multirow{3}{*}{0} & 1 & 5443 & 504.28 & \multirow{3}{*}{517.30} & 2.40 & \multirow{3}{*}{2.40} & 1.90 & \multirow{3}{*}{1.87} \\
\hline & 2 & 5557 & 547.22 & & 2.50 & & 1.70 & \\
\hline & 3 & 5121 & 500.39 & & 23.30 & & 2.00 & \\
\hline \multirow{3}{*}{1} & 4 & 5879 & 552.82 & \multirow{3}{*}{538.83} & 2.60 & \multirow{3}{*}{2.37} & 1.55 & \multirow{3}{*}{1.72} \\
\hline & 5 & 5634 & 542.01 & & 2.30 & & 1.70 & \\
\hline & 6 & 5339 & 521.67 & & 2.20 & & 1.90 & \\
\hline \multirow{3}{*}{2} & 7 & 6432 & 600.34 & \multirow{3}{*}{567.31} & 2.10 & \multirow{3}{*}{2.27} & 1.55 & \multirow{3}{*}{1.63} \\
\hline & 8 & 5684 & 542.64 & & 2.40 & & 1.75 & \\
\hline & 9 & 6373 & 558.97 & & 2.30 & & 1.60 & \\
\hline \multirow{3}{*}{3} & 10 & 6622 & 622.77 & \multirow{3}{*}{633.02} & 2.10 & \multirow{3}{*}{2.23} & 1.60 & \multirow{3}{*}{1.57} \\
\hline & 11 & 6373 & 613.14 & & 2.40 & & 1.65 & \\
\hline & 12 & 7158 & 663.13 & & 2.20 & & 1.45 & \\
\hline \multirow{3}{*}{4} & 13 & 7407 & 694.48 & \multirow{3}{*}{682.08} & 2.00 & \multirow{3}{*}{2.10} & 1.30 & \multirow{3}{*}{1.42} \\
\hline & 14 & 7543 & 697.82 & & 2.10 & & 1.55 & \\
\hline & 15 & 6849 & 653.93 & & 2.20 & & 1.40 & \\
\hline \multirow{3}{*}{5} & 16 & 7593 & 716.21 & \multirow{3}{*}{714.22} & 2.00 & \multirow{3}{*}{2.00} & 1.30 & \multirow{3}{*}{1.33} \\
\hline & 17 & 7770 & 714.57 & & 2.20 & & 1.32 & \\
\hline & 18 & 7707 & 711.87 & & 1.80 & & 1.37 & \\
\hline \multirow{3}{*}{7} & 19 & 7566 & 716.89 & \multirow{3}{*}{731.06} & 1.60 & \multirow{3}{*}{1.50} & 1.10 & \multirow{3}{*}{1.20} \\
\hline & 20 & 8015 & 748.10 & & 1.40 & & 1.30 & \\
\hline & 21 & 7453 & 728.21 & & 1.50 & & 1.20 & \\
\hline
\end{tabular}

The indirect tensile strength test shows that the addition of polypropylene granules has improved the properties of asphalt mixtures. This improvement in properties is shown by the following figures:

1- effect on indirect tensile strength: As shown in Fig. 8, the indirect tensile strength of the asphalt mix is generally increased with the increase in the percentage of the added polypropylene granules, where the increase in resistance is weak in the few percentages of the granules and the effective effect begins for polypropylene granules on tensile strength after $2 \%$ of the addition, which increases about $32 \%$ higher than the reference mixture at percentages $4 \%$ of the addition. Then effect of the granules on improving the resistance of the indirect tensile strength decreased by $4 \%$ of the addition, after which the granule effect improved. Indirect tensile strength. This is explained by the fact that with the addition of polypropylene granules to the asphalt binder, it changes its chemical composition to form a homogeneous mixture with greater adhesion properties which increases the cohesion of the asphalt mixtures and thus increases its resistance to stresses.

2- Influence on horizontal and vertical deformation: Both horizontal and vertical deformation reflect the plastic deformation of the test samples at failure in both the vertical direction on the loading axis and the parallel direction of the loading axis respectively, as shown in Figure 9, which explicates the relationship between granules added, and Figure 10 expressing the relationship of the vertical deformation with the ratio of the added granules, both horizontal and vertical deformation decrease with increasing percentage of polypropylene granules. This is explained by increasing the hardness and hardness of the asphalt binder with increase of granules in asphalt that reduces the flexibility and thus reduces the horizontal and vertical Flow values. 


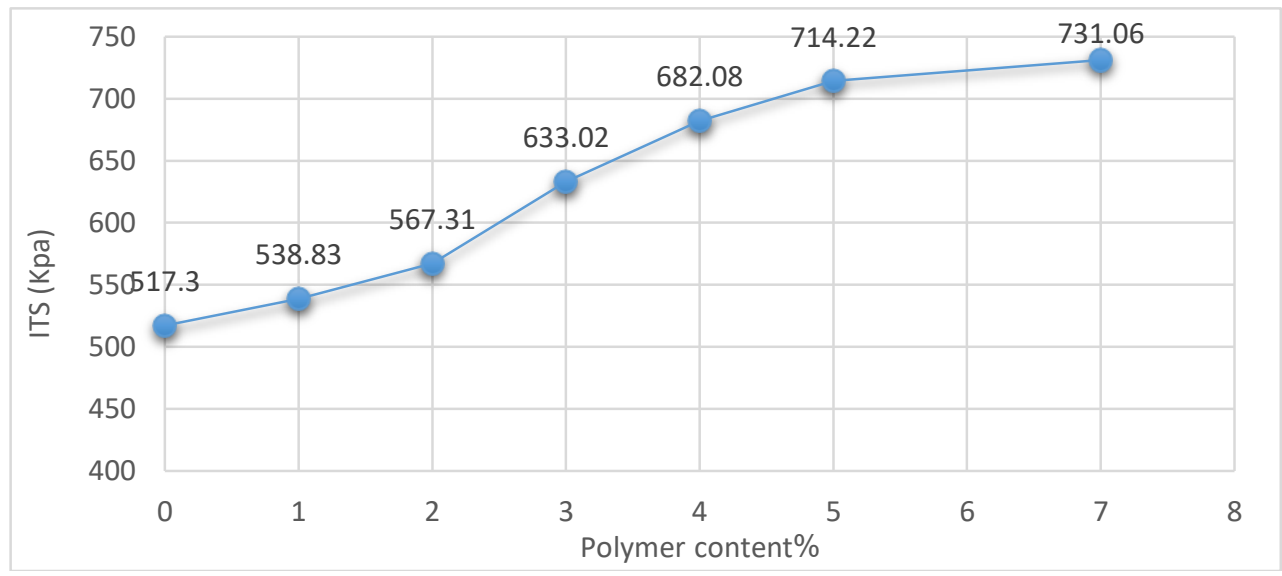

Figure 8 The relationship between Polymer content $\%$ and ITS

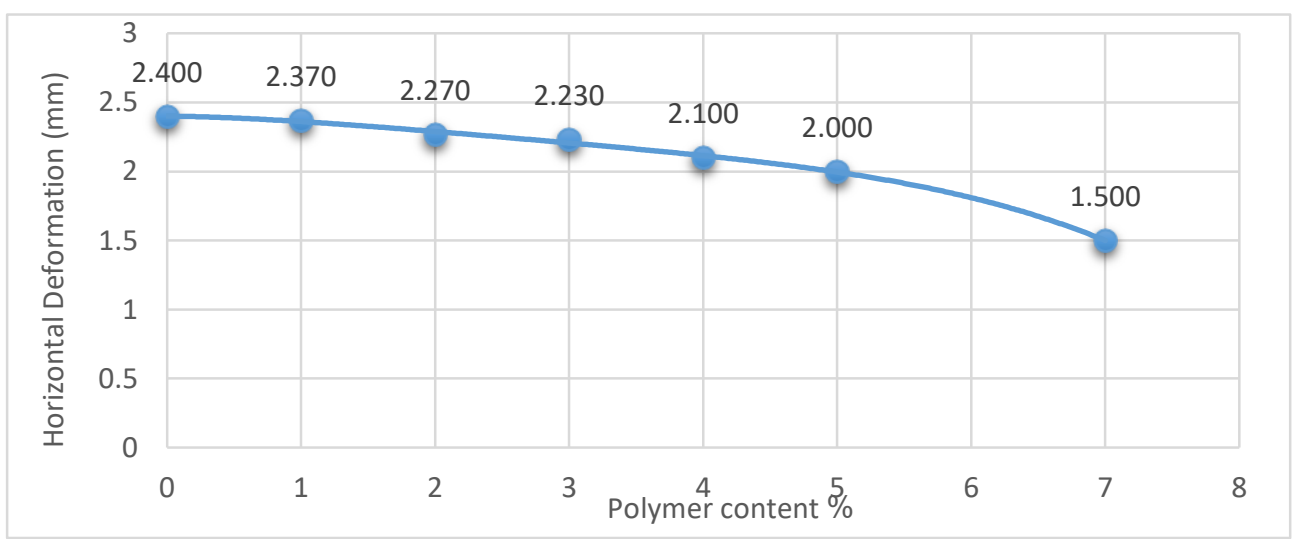

Figure 9 The Relationship between Polymer content and Horizontal Deformation of ITS

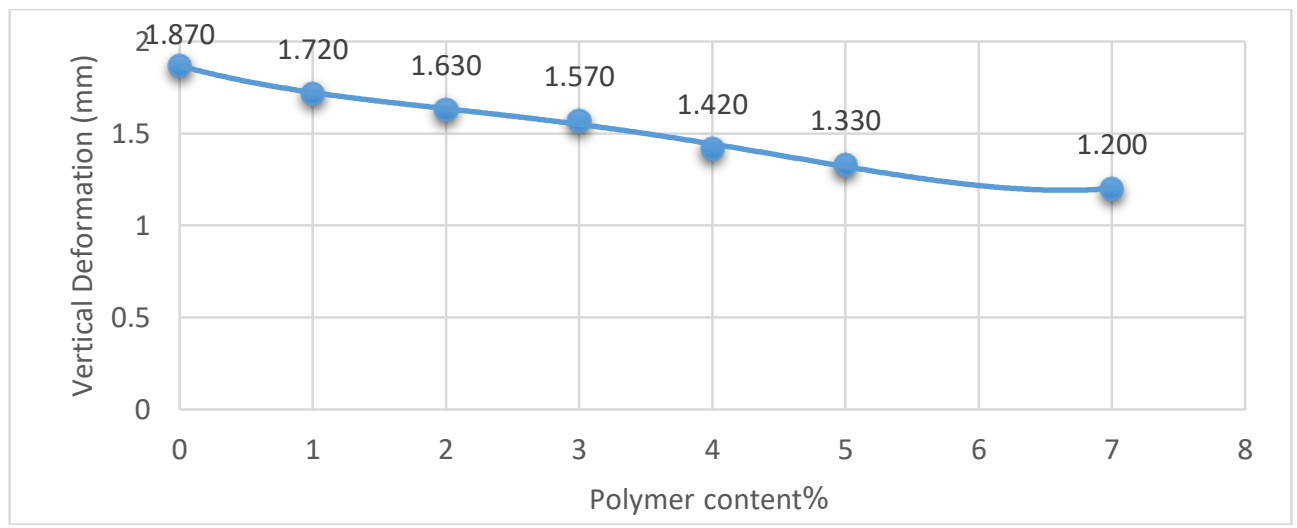

Figure 10 The Relationship Between Polymer content\% and Vertical Deformation of ITS 


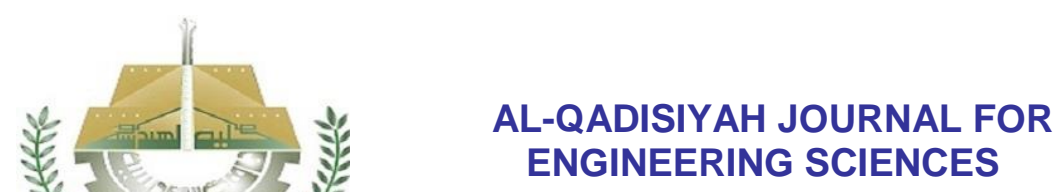

ENGINEERING SCIENCES
Vol. 11, No. 2

ISSN: $1998-4456$

\subsubsection{Effect of polymer on HMA volumetric properties}

Volumetric properties : the maximum theoretical density results from Fig 11 clarifies that significant reduction in the values with increasing polymer content in the mix, and this may backs to polymer specific density, which is lower than bitumen density as clarifed in Fig 11. Also, a slight noticeable increase in the air voids content has been noticed with increasing amount of the polymer content. All AV\% values were within the limitation (between 3-5). Further, from Fig 12, addition of polymer has increased VMA\%, because of higher air voids content. Also, all the percentage are within the GSRB limitation (above 14\%) as cleared in Figure 13. Fig 14 present the relation between polymer content and VFB\%. Increasing amount of polymer resulted in sufficient negative change on VFB\% values. The polymer content up to $4 \%$ reflected VFB\% within the limitations $(<70)$.

Returning to the design requirements of the asphalt mixture as demonstrated in Table 5 , the changes in the properties of asphalt mixtures due to the addition of polypropylene granules remained within the permissible limits. Therefore, the best percentage of granules added is the percentage that improves all or most mechanical properties of asphalt mixtures. As a result of the study and analysis of the results of the indirect tensile strength test, it has been concluded that addition of $4 \%$ of the polypropylene granules is the best percentage that gives optimal improvement and effective of the different properties of the asphalt mixture. The selected percentage was efficient to enhance the mechanical properties of the test program and reducing vertical and horizontal deformations, without effecting other volumetric and mechanical properties and makes them out of the limitations.

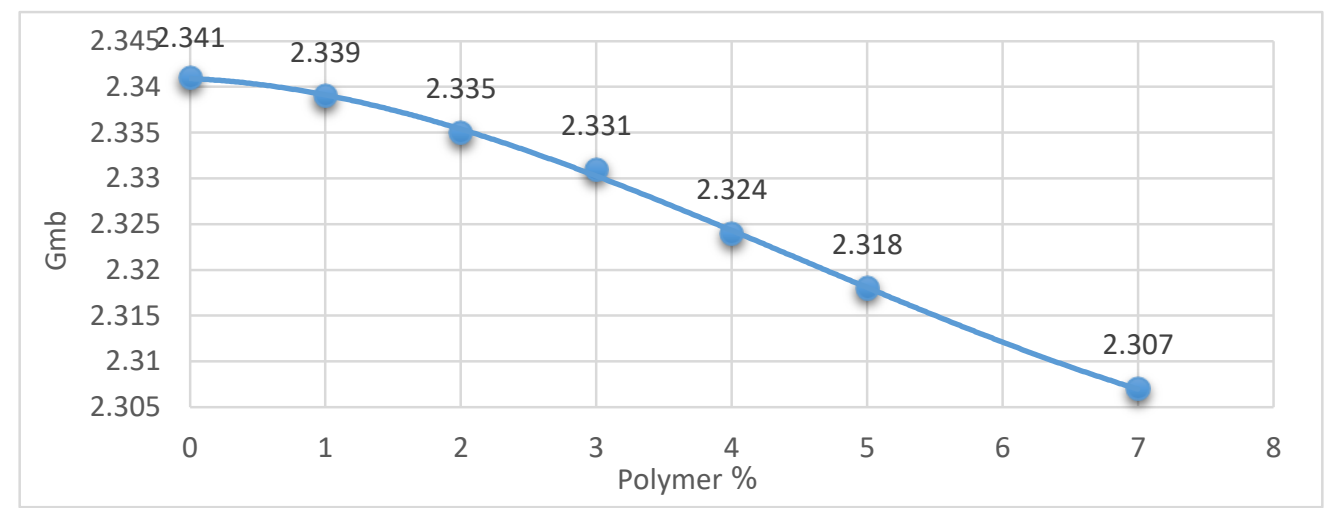

Figure 11 The relationship between polymer content and Gmb 


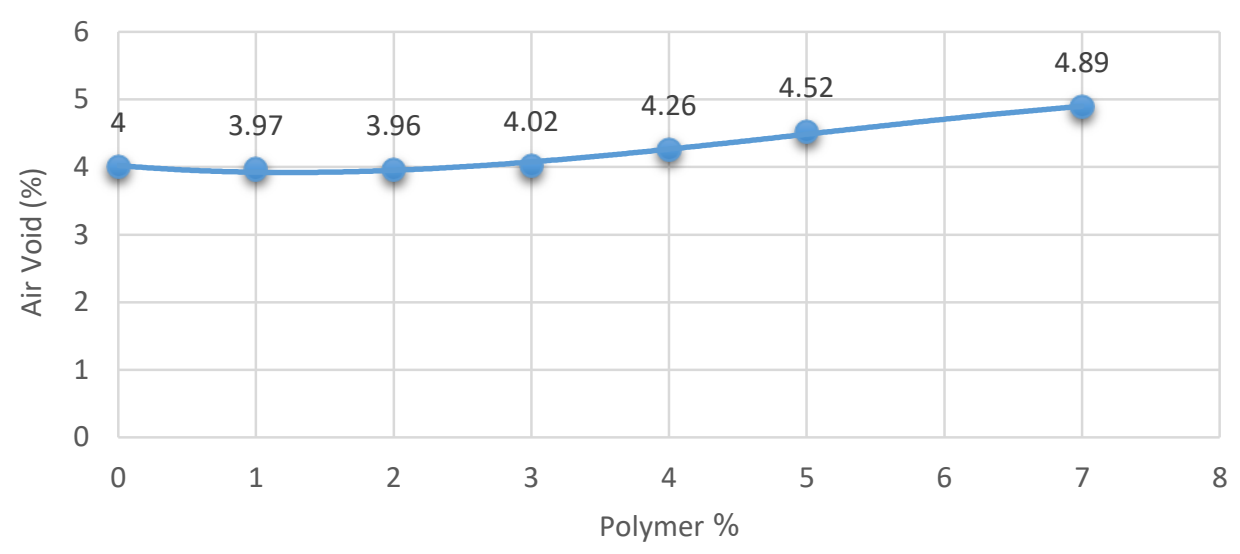

Figure 12 The relationship between polymer content and air void

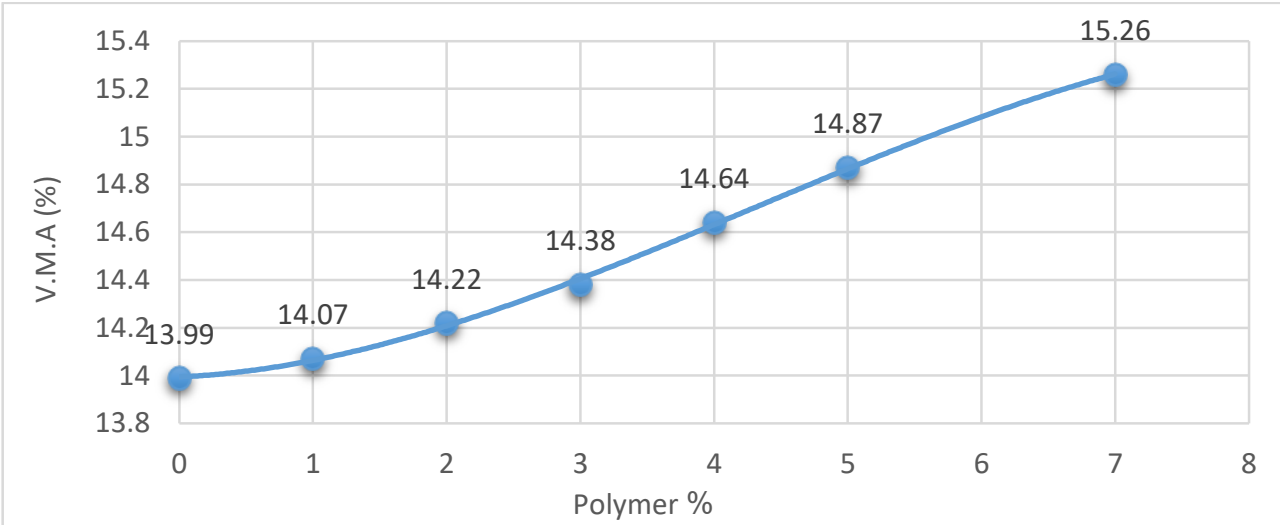

Figure 13 The relationship between polymer content and V.M.A

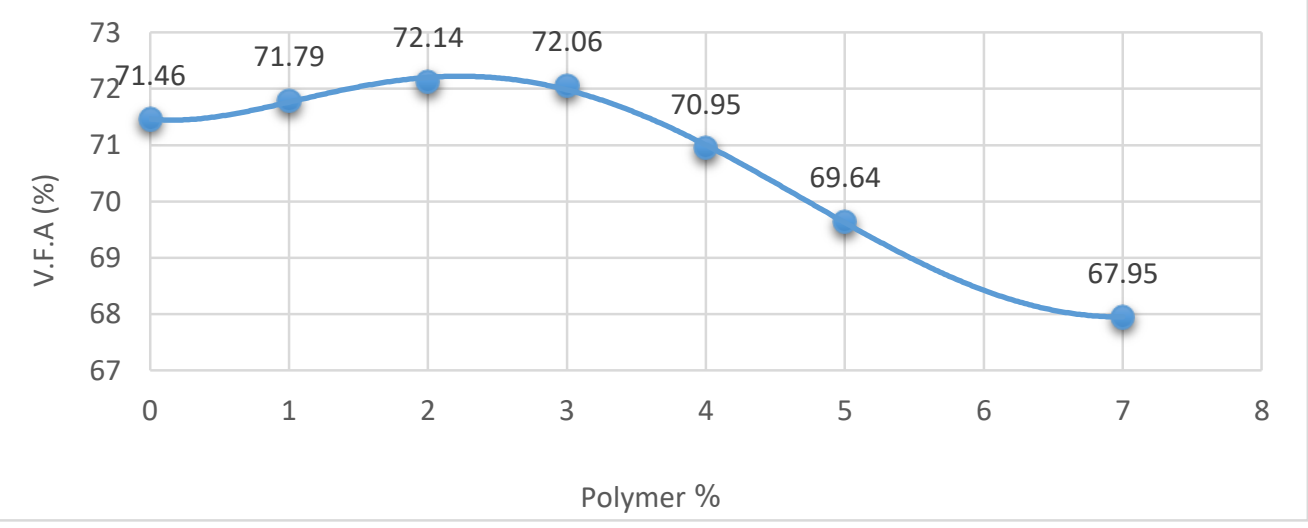

Figure 14 The Relationship Between Polymer content and V.F.A 
AL-QADISIYAH JOURNAL FOR ENGINEERING SCIENCES
Vol. 11, No. 2

ISSN: 1998-4456

\section{CONCLUSIONS}

Based on previous analysis of Figures, The main conclusions can be drawn:

1- Polymer modified asphalt method showed higher mechanical performance than the control mixtures.

2- Increasing amount of polymer content within HMA mix resulted in ITS enhancement, for all studied percentages of the induced polymer.

3- Polymer has increased mixture strength by reducing vertical and horizontal deformations further to increasing ITS strength.

4- Polypropylene granules showed negative effect on HMA volumetric properties. Increasing amount of polymer has increased voids in mineral aggregates and air voids content, and reducing density and voids filled with bitumen.

5- The optimum percentage of polymer content was $4 \%$ based on the mechanical and volumetric properties, since other volumetric properties like VFB\% showed values out of the standards (70-85\%) at higher polymer content than $4 \%$.

\section{REFERENCES}

1. ABD-A.M.AL-D, I. 2003. Evaluation of the Factors Influencing theTensile Properties of Asphalt Paving Materials.

2. ASTM 2000. Standard Test Method for Softening Point of Bitumen (Ring-and-Ball Apparatus). D36, American Society for Testing Material, West Conshohocken, PA, United States.

3. ASTM 2005. Standard Test Method for Flash and Fire Points by Cleveland Open Cup Tester D92, American Society for Testing Material, West Conshohocken, PA, United States.

4. ASTM 2007. Standard Test Method for Ductility of Bituminous Materials. D113, American Society for Testing Material, West Conshohocken, PA, United States.

5. ASTM 2009. Standard Test Method for Density of Semi-Solid Bituminous Materials (Pycnometer Method). D70, American Society for Testing Material, West Conshohocken, PA, United States.

6. ASTM 2012. Standard Test Method for Indirect Tensile (IDT) Strength of Bituminous Mixtures. D6931, American Society for Testing Material, West Conshohocken, PA 19428-2959, United States.

7. ASTM 2014. Standard Test Method for Effects of Heat and Air on Asphaltic Materials (Thin-Film Oven Test). D1754, American Society for Testing Material, West Conshohocken, PA, United States.

8. ASTM 2015a. Standard Test Method for Marshall Stability and Flow of Asphalt Mixtures. D6927, American Society for Testing Material, West Conshohocken, PA, United States.

9. ASTM 2015b. Standard Test Method for Penetration of Bituminous Materials. D5, American Society for Testing Material, West Conshohocken, PA, United States.

10. AWWAD, M. T. \& SHBEEB, L. 2007. The use of polyethylene in hot asphalt mixtures. American Journal of Applied Sciences, 4, 390-396.

11. BUTTON, J. \& LYTTON, R. 2007. Guidelines for using geosynthetics with hot-mix asphalt overlays to reduce reflective cracking. Transportation Research Record: Journal of the Transportation Research Board, 111-119.

12. GSRB 2003. GENERAL SPECIFICATION FOR ROADS AND BRIDGES,SECTION R9. Iraq.

13. KALANTAR, Z. N., KARIM, M. R. \& MAHREZ, A. 2012. A review of using waste and virgin polymer in pavement. Construction and Building Materials, 33, 55-62. 
14. KHAN, T. A., SHARMA, D. \& SHARMA, B. 2009. Performance evaluation of waste plastic/polymer modified bituminous concrete mixes.

15. NAVARRO, F., PARTAL, P., MARTíNEZ-BOZA, F. \& GALLEGOS, C. 2007. Influence of processing conditions on the rheological behavior of crumb tire rubber-modified bitumen. Journal of applied polymer science, 104, 1683-1691.

16. POLACCO, G., BERLINCIONI, S., BIONDI, D., STASTNA, J. \& ZANZOTTO, L. 2005. Asphalt modification with different polyethylene-based polymers. European Polymer Journal, 41, 2831-2844. 